\title{
AQUISIÇÃO DE LEITURA EM CRIANÇAS COM TEA E O MÉTODO FÔNICO
}

\author{
https://dx.doi.org/10.48097/2674-8673.2021n4p02
}

\author{
Isabella Alessandra Oliveira de Paula ${ }^{1}$ \\ Maria Dalva da Silva ${ }^{2}$ \\ Patrícia da Paz de Siqueira ${ }^{3}$ \\ Fabiana Maria da Silva ${ }^{4}$
}

\section{RESUMO}

Ainda hoje há muita gente que acha que as pessoas com TEA não aprendem. Entretanto, a inclusão na sociedade contemporânea mostra que a alfabetização de modo pleno pode ser aprendida e deve ser ofertada como garantia de um direito adquirido. Assim, temos por objetivo ampliar o olhar sobre os processos de alfabetização de crianças com TEA no presente artigo. Para isso buscamos relatar os resultados de um estudo de revisão com pesquisas publicadas em artigos científicos, analisando qual método é mais indicado para os autistas em processo de alfabetização. Os resultados das pesquisas revelam que esses indivíduos, tipicamente, evidenciam déficits no processo de aquisição de competências em leitura. $\mathrm{O}$ trabalho discute sobre os métodos de ensino, seus prós e contras, buscando entender os modelos interventivos que revelam o quanto a equipe multidisciplinar é essencial para o desenvolvimento em todos os aspectos dessas crianças.

Palavras-chave: Método fônico. Métodos de alfabetização. Consciência fonológica. Aquisição da leitura. TEA.

Data de submissão: 27/09/2020

Data de aprovação: $17 / 11 / 2020$

\begin{abstract}
Even today, many people think that people with ASD do not learn. However, inclusion in contemporary society shows that full literacy can be learned and must be offered as a guarantee of an acquired right. Thus, we aim to broaden the look at the literacy processes of

${ }^{1}$ Discente do Curso de Licenciatura em Pedagogia da Faculdade Metropolitana da Grande Recife. E-mail: isabellaalessandraapx@hotmail.com

2 Discente do Curso de Licenciatura em Pedagogia da Faculdade Metropolitana da Grande Recife. E-mail: dalva9945@gmail.com

${ }^{3}$ Discente do Curso de Licenciatura em Pedagogia da Faculdade Metropolitana da Grande Recife. E-mail: paty201036@hotmail.com

${ }^{4}$ Orientadora/Docente do Curso de Pedagogia da Faculdade Metropolitana da Grande Recife. E-mail: fabiana.silva1@gmail.com
\end{abstract}


children with ASD in this article. To this end, we seek to report the results of a review study with research published in scientific articles on literacy methods, analyzing which method is most suitable for autistic people in the literacy process. The results of the surveys reveal that these individuals typically show deficits in the process of acquiring reading skills. The work discusses teaching methods, their pros and cons, seeking to understand the intervention models that reveal how essential the multidisciplinary team is for the development of all aspects of these children.

Keywords: Phonic method. Literacy methods. Phonological awareness. Reading acquisition. ASD.

\section{INTRODUÇÃO}

Esta pesquisa, de abordagem bibliográfica do tipo qualitativa, exploratória, trata do tema autismo e o método fônico utilizado no processo de leitura de crianças autistas sob a perspectiva da inclusão. O espectro autista é tema de um grande debate na literatura, sobretudo após a lei no 12.764 de 27 de dezembro de 2012 que institui a Política Nacional de Proteção dos Direitos da Pessoa com Transtorno do Espectro Autista.

É sabido que os estudantes com espectro autista devem estar inclusos em salas de aulas regulares, no entanto, também se sabe das dificuldades subjacentes ao processo de inclusão desses estudantes, pois a escola e os professores precisam adaptar seu repertório de atividades, repensar o Projeto Político Pedagógico (PPP) e suas metodologias a partir de práticas inclusivas e heterogêneas.

Assim, o recorte desta pesquisa está demarcado a partir da necessidade do estudante autista em sala de aula, no que diz respeito ao seu processo de aquisição da leitura. A Organização Mundial da Saúde (OMS) estima que há 70 milhões de pessoas com autismo em todo o mundo, sendo 2 milhões somente no Brasil. Estima-se que uma em cada 88 crianças apresenta traços de autismo, com prevalência cinco vezes maior em meninos.

Esses números indicam a importância de falar sobre o assunto. Diversos atores alguns pais e familiares, profissionais, acadêmicos, gestores, os próprios autistas e outros ativistas - têm promovido ampla discussão a partir de diferentes perspectivas. No entanto, nossa pesquisa busca contribuir para o debate sobre os métodos que podem ajudar na aquisição da leitura por estudantes autistas.

As escolas estão recebendo cada vez mais estudantes autistas que precisam, assim como os demais estudantes, adquirir competências que os emancipe, que os ajude a construir sua cidadania. A leitura é uma dessas competências primordiais para que o indivíduo construa sua cidadania e se sinta parte do contexto social. É também uma atividade complexa que exige a mobilização de várias habilidades, sobretudo para estudantes autistas. 
Encontrar o método de alfabetização adequado e ter conhecimento sobre todos os outros métodos de alfabetização para crianças com TEA é nosso objetivo geral. Achamos no método fônico esse respaldo nos diversos artigos acadêmicos e livros pesquisados, além da criança com TEA ter mais facilidade de aprender com esse método.

Na disciplina de Estágio Supervisionado III estivemos em uma ONG voltada para crianças e adolescentes com deficiências físicas e TEA. Nas aplicações das aulas e no convívio com os usuários confirmamos nossa certeza na definição do tema da nossa pesquisa, contribuindo para entender melhor sobre as diferenças, necessidades e métodos capazes de ajudar no desenvolvimento dos mesmos.

Atualmente, há um amplo debate tanto na academia quanto na sociedade em geral sobre o autismo, a partir de diferentes perspectivas. Nossa pesquisa busca contribuir para o debate sobre métodos que podem ajudar na aquisição da leitura por estudantes autistas.

É nesse sentido que a presente pesquisa é importante, pois quanto mais discutir o "como se faz" e as boas práticas, mais material de referência os profissionais da educação podem consultar para ajudar a construir e ampliar seu repertório de práticas pedagógicas.

\section{FUNDAMENTAÇÃO TEÓRICA}

Neste trabalho serão abordados os conceitos fundamentais da nossa pesquisa que discorre sobre o TEA (Transtorno do Espectro do Autismo) e como se promove a alfabetização e os processos neurais que corroboram com a aprendizagem. Na alfabetização serão abordados os diversos métodos, recaindo o foco sobre o método fônico.

\section{TEA: história e aprendizagem}

O termo "autismo" é oriundo da palavra grega autos que significa "próprio" ou "de si mesmo". O Transtorno do Espectro do Autismo (TEA) é um transtorno do neurodesenvolvimento, caracterizado por padrões de comportamentos repetitivos e dificuldade na interação social, afetando o desenvolvimento da pessoa. (ORRÚ, 2007).

Autismo é um espectro e o termo justifica-se por conta da imensa variabilidade de características clínicas que se observa. Algumas pessoas com autismo não falam, outras não param de falar, algumas falam de forma incomum, entendem pouco, não entendem, ou entendem de forma única.

Determinadas pessoas com TEA podem viver de forma independente, mas algumas com deficiências mais graves vão precisar de mais atenção, terapias e apoio durante toda a vida. Klin (2006) esclarece que: 
O autismo é uma desordem generalizada do desenvolvimento, razão pela qual é caracterizada pela presença de um conjunto de sintomas relacionados, e não por um único sintoma isolado. Entre suas características usuais está a presença de uma deterioração qualitativa na interação social, bem como padrões estereotipados e restritos de comportamentos, atividades e interesses. Não há atraso clinicamente significativo no desenvolvimento cognitivo, e não há atrasos na aquisição de linguagem. (KLIN, 2006, p. 78).

O nível intelectual pode variar desde comprometimento severo até a presença de aptidões cognitivas e hiperfoco até a genialidade. Conforme matéria de Vanessa Fajardo, publicada no Portal G1:

\begin{abstract}
O autismo manifesta-se de maneiras diferentes em cada indivíduo, mas todos têm em comum as dificuldades de interação social, alterações de padrões de comunicação verbais e não verbais, interesses restritos, inflexibilidade cognitiva e comportamental, dificuldades para a abstração de conceitos, fraca coerência central a favor do processamento de detalhes, interpretação literal da linguagem, dificuldades em funções executivas e de planejamento. (FAJARDO, 2010, p. 48).
\end{abstract}

Os primeiros sinais de uma criança com TEA começa antes dos três anos de vida, entre 12 e os 18 meses, e fica mais perceptivo com o atraso de linguagem e na fala, o que leva os pais ou responsáveis a cogitarem dificuldades na audição.

Outro fator preponderante é no campo das relações sociais da criança com TEA. Há um deficit significativo visto através de um contínuo isolamento social até dos seus parceiros ou familiares de tal forma que eles não revelam nem suas necessidades básicas. (KLIN, 2006).

Nem todos os autistas são assim. Alguns são carinhosos, mas para isso precisam ter confiança e uma relação pessoal com a outra pessoa. $\mathrm{O}$ convívio quanto às estereotipias, ecolalias e outros transtornos que alguns autistas possuem é que definem os tipos de terapias, tratamentos clínicos, metodologia e métodos de alfabetização escolar adequados, pois cada um ser é único, mesmo com algumas características iguais.

\title{
Métodos de alfabetização
}

Antes de abordar o método fônico é interessante explicar brevemente outros métodos de alfabetização para que tenhamos uma visão mais ampliada a respeito do tema proposto. $\mathrm{O}$ processo de alfabetização já passou por diversas descobertas ao longo da história recente, com métodos sintéticos e analíticos. Dentre eles, podemos citar o alfabético ou soletração, método fônico ou fonético, método silábico, palavração, sentenciação, e método global.

O método alfabético ou de soletração é um dos mais antigos e há menções ao seu uso desde a antiguidade (MORATTI, 2006). A partir de vários materiais e de depoimentos de alunos constata-se em sua aplicação uma sequência modelar: a decoração oral das letras do alfabeto, seu reconhecimento posterior em pequenas sequências e numa sequência de todo o alfabeto e, finalmente, de letras isoladas. 
No método de sentenciação, a unidade é a sentença que, depois de reconhecida globalmente e compreendida, será decomposta em palavras e, finalmente, em sílabas. Um outro procedimento descrito na história desse método é a estratégia de comparar palavras e isolar elementos conhecidos nelas, para ler e escrever palavras novas. (SOARES, 2004).

Esse método foi um dos primeiros dos métodos globais a ser utilizado, porém começou a ser aplicado somente no fim do século XIX. Ele se baseia na construção de textos, contos, ou histórias já conhecidas. Após a apresentação total do texto, é desmembrada uma frase que será repetida várias vezes. $\mathrm{O}$ estudo da frase resultará no estudo das palavras e depois nas sílabas e a composição de novas palavras com as sílabas estudadas. O processo envolve análise das partes maiores (o texto, as frases) para chegar às partes menores (palavras e sílabas). Por isso o método global é também conhecido como analítico. (MORATTI, 2006).

\section{Método fônico}

O método fônico de alfabetização é o sistema que consiste em ensinar os sons da primeira letra de cada palavra. A partir daí a pronúncia completa do vocábulo é construída a partir da mistura de cada som, permitindo que a criança leia toda e qualquer palavra.

O método fônico ou fonético integra o conjunto dos métodos sintéticos que privilegiam as correspondências grafofônicas. Seu princípio de organização é a ênfase na relação direta entre fonema e grafema, ou seja, entre o som da fala e a escrita. Este método surge como uma reação às críticas da soletração, e seu uso é mencionado na França, por Vallange, em 1719; na Alemanha, por Enrique Stefhani, em 1803; e é trabalhado por Montessori, na Itália, em 1907.

Neste método o ensino se inicia pela forma e pelo som das vogais, seguidas pelas consoantes. Cada letra (grafema) é aprendida como um som (fonema) que, junto a outros fonemas, pode formar sílabas e palavras. Para o ensino dos sons, há uma sequência que deve ser respeitada - dos mais simples para os mais complexos.

O método fônico é pautado na estrutura fonológica das palavras. Zorzi e Capellini (2008) acreditam que a consciência fonológica é um dos quesitos indispensáveis na alfabetização. Para eles a intervenção realizada pelo professor necessita desse fator, pois é necessário que haja o conhecimento por parte do aluno de que as palavras se constituem de pequenas unidades sonoras, denominadas fonemas. Reforçando nossa colocação, a noção de fonema é um dos pilares do sistema alfabético de escrita. São os fonemas que se transformam em letras.

Tanto em sociedades letradas como em não letradas esse método de ensino tende a ter mais sucesso, pois o mesmo favorece o princípio alfabético e não exige que a criança traga 
obrigatoriamente consigo uma bagagem de conhecimentos antes de ingressar na vida escolar, tendo em vista que algumas crianças, na maioria das vezes, só têm a oportunidade de contato com o universo da leitura na escola. (SOARES, 2004).

Há, na literatura médica, uma série de contribuições que evidenciam a eficácia do método fônico. Um dos nomes mais celebrados neste meio é o Dr. Fernando Capovilla, da Universidade de São Paulo (USP). O especialista afirma que o método fônico é ideal por mapear a fala. Além disso, o professor salienta que cada criança deve receber um tipo de tratamento adequado à sua necessidade.

Essa adequação vai ser um fator determinante no aprendizado da criança, sendo ela autista ou não, e para isso os profissionais devem conhecer todos os métodos de alfabetização para assim introduzir o método mais eficiente para cada necessidade. Esse trabalho com os autistas é feito em conjunto com profissionais de uma equipe multidisciplinar.

Segundo Capovilla \& Capovilla (2007), pode haver alunos que fracassam na escola, mas que não são incapazes de raciocinar ao aprender, porém, as dificuldades destes são observadas "tarde demais", após a ocorrência de muitos fracassos.

Para entender sobre esse processo da aquisição da leitura recorremos ao artigo científico intitulado "O método fônico sob a perspectiva neurológica" (BARBOSA \& SOUZA, 2017). Este trabalho discorre sobre a neurociência que também tem contribuído bastante para o melhor entendimento do que possivelmente ocorre quando a criança faz a tentativa de transposição dos grafemas para fonemas, ou seja, de que forma o nosso cérebro sintetiza e interpreta as informações sensoriais advindas do ambiente no momento da leitura, mais especificamente, as visuais e auditivas.

Ao falar especificamente da aquisição da leitura, e com base em fundamentos neuropsicológicos, estudos demonstram que existe um caminho neurológico (sequência de processamentos) já programado para esta atividade - processamento botton-up - em que a decodificação ocorre das partes para o todo. O que se leva a entender que, para alfabetizar uma criança, o método mais proveitoso seria aquele que considera a predefinição biopsicológica ao qual nosso cérebro está preparado, que seria o método fônico.

Deste modo, para compreendermos o funcionamento neuropsicológico diante da aprendizagem da leitura pelo método fônico, "é importante que tenhamos um conhecimento básico de como a informação circula pelo cérebro". (COSENZA, 2011).

Desta forma Capovilla \& Capovilla (2007) defendem em seus estudos que pesquisas têm mostrado uma superioridade de métodos pautados na relação fonema-grafema, denotando-os como de maior eficácia para a alfabetização. 
Publicado em 2015, na revista Brain and Language, um estudo da Escola Superior de Educação e do Instituto de Neurociência Stanford, de coautoria do Professor Bruce McCandliss, fornece algumas evidências de que uma estratégia de ensino específica para a leitura tem um impacto neural direto. Foi realizado um teste de leitura enquanto as ondas cerebrais eram monitoradas, sendo possível perceber que respostas do cérebro muito rápidas para as palavras recém aprendidas foram influenciadas pela forma como eram ensinadas.

O professor Bruce McCandliss descobriu que os aprendizes de leitores que se concentram na relação grafema/fonema (letra/som), ou método fônico, aumentam a atividade cerebral na área destinada à leitura, o lado esquerdo do cérebro, que engloba as regiões visuais e de linguagem.

Devido às diferenças obtidas por exames de imagem sabe-se que o cérebro da criança com TEA funciona de forma diferenciada. Em muitos casos, isso requer também uma diferenciação no estilo de aprendizagem visual e auditivo, fazendo com que a memória auditiva facilite a aquisição da leitura nestas crianças pelo método fônico.

Após discussão sobre os conceitos a respeito do método fônico, selecionamos 5 artigos para investigar a relevância desse método no desenvolvimento da leitura com crianças com autismo.

\section{Quadro 1 - Importância do método fônico para aquisição da leitura}

\begin{tabular}{|c|c|c|}
\hline Título e data da publicação & Autores & $\begin{array}{l}\text { Importância do método fônico para } \\
\text { aquisição de leitura em crianças } \\
\text { autistas }\end{array}$ \\
\hline $\begin{array}{l}\text { Processos de Leitura em } \\
\text { Educandos com Autismo: um } \\
\text { Estudo de Revisão. (2016) }\end{array}$ & $\begin{array}{l}\text { Débora Regina de Paula } \\
\text { NUNES; Elizabeth Cynthia } \\
\text { WALTER }\end{array}$ & $\begin{array}{l}\text { Através do método fônico, consciência } \\
\text { fônica e consciência fonológica, conclui- } \\
\text { se que a decodificação com o ensino } \\
\text { explícito das correspondências grafemas e } \\
\text { fonemas contribui de sobremaneira para } \\
\text { compreensão do princípio alfabético. }\end{array}$ \\
\hline $\begin{array}{l}\text { Problemas de aquisição de } \\
\text { leitura e escrita: efeitos de } \\
\text { déficit de discriminação } \\
\text { fonológica, velocidade de } \\
\text { processamento de memória. } \\
(2007)\end{array}$ & $\begin{array}{l}\text { Fernando C. Capovilla; } \\
\text { Alessandra G. S. Capovilla }\end{array}$ & $\begin{array}{l}\text { Procedimentos } \quad \text { voltados ao } \\
\text { desenvolvimento da consciência } \\
\text { fonológica, como é o método fônico, são } \\
\text { capazes de melhorar substancialmente a } \\
\text { competência de leitura e escrita. }\end{array}$ \\
\hline $\begin{array}{l}\text { O método fônico sob a } \\
\text { perspectiva neuropsicológica. } \\
(2017)\end{array}$ & $\begin{array}{l}\text { BARBOSA, } \\
\text { DaianyToffaloni; }\end{array}$ & $\begin{array}{l}\text { O método fônico respeita a arquitetura } \\
\text { cerebral no aprendizado da leitura visual e } \\
\text { motora (fala) e a neurociência contribui } \\
\text { para crianças na transposição de grafemas } \\
\text { para fonemas com processamento }\end{array}$ \\
\hline
\end{tabular}




\begin{tabular}{|c|c|c|}
\hline & & fonológico e pronuncia dos fonemas. \\
\hline $\begin{array}{l}\text { As contribuições do método } \\
\text { fônico nos anos iniciais } \\
\text { de alfabetização. (2015) }\end{array}$ & Tatiane Salina & $\begin{array}{l}\text { O método contribui com diversas } \\
\text { habilidades importantes a serem } \\
\text { desenvolvidas, como a aquisição e } \\
\text { desenvolvimento da consciência } \\
\text { fonológica, auxilia na boa dicção e } \\
\text { prepara o aluno para compreenda melhor } \\
\text { textos. }\end{array}$ \\
\hline $\begin{array}{l}\text { Efeitos de uma intervenção na } \\
\text { abordagem fônica em alunos } \\
\text { com dificuldades de } \\
\text { alfabetização. (2012) }\end{array}$ & $\begin{array}{lr}\text { Maria Inês de } & \text { Souza } \\
\text { Vitorino Justino; } & \text { Sylvia } \\
\text { Domingos Barrera. } & \end{array}$ & $\begin{array}{l}\text { Ao privilegiar o ensino sistemático e } \\
\text { explícito das letras do alfabeto e dos } \\
\text { fonemas a elas associados, favorece o } \\
\text { desenvolvimento da consciência } \\
\text { fonológica, habilidade metalinguística } \\
\text { básica para o domínio do princípio } \\
\text { alfabético, princípio esse que constitui a } \\
\text { chave-mestra para o funcionamento do } \\
\text { código, que reside no domínio das } \\
\text { correspondências grafo-fonêmicas. }\end{array}$ \\
\hline
\end{tabular}

Fonte: as autoras

A leitura dos artigos nos indicou que a relevância do método fônico para o desenvolvimento da aquisição da leitura pelas crianças autistas está relacionada à consciência fonológica que é a habilidade da manipulação de sons. Temos a percepção de sons que algumas palavras têm, com sons parecidos, ou algumas palavras que terminam e começam com o mesmo som. O ensino de grafemas e fonemas facilita a compreensão e a leitura, inclusive de palavras desconhecidas.

A consciência fonológica refere-se tanto à consciência de que a fala pode ser segmentada quanto à habilidade de manipular tais segmentos, e se desenvolve gradualmente à medida que a criança vai tomando consciência do sistema sonoro da língua, ou seja, de palavras, sílabas e fonemas como unidades identificáveis. (Capovilla \& Capovilla, 2007).

A palavra diminuída pode ser manipulada, avançando no processo de alfabetização. Quando a criança percebe que os sons das palavras se repetem em várias palavras e essa sequência de sons expressa, nomeia a escrita de palavras e objetos, então a compreensão acontece.

Podemos entender que cada criança é única e vai ter habilidades e dificuldades diferentes. Buscamos analisar os vários métodos de alfabetização e as bases históricas na aprendizagem da criança com TEA para adequar o que vai ser aplicado com cada criança com 
TEA, no aprendizado na leitura. Para isso procuramos compreender o funcionamento do método fônico na alfabetização.

\section{METODOLOGIA}

A presente pesquisa possui natureza qualitativa, que nos parece mais indicada para as pesquisas em educação, pois considera que há uma relação dinâmica entre o mundo real e o sujeito, isto é, um vínculo entre o mundo objetivo e a subjetividade do sujeito que não pode ser traduzido em números.

Para dar conta de nossos objetivos optamos por realizar uma pesquisa exploratória, a partir de levantamento bibliográfico, como técnica de coleta de dados.

Assim, pesquisamos na plataforma cientifica da Scielo sobre o tema de alfabetização pelo método fônico em crianças com TEA no desenvolvimento da aquisição da leitura.

Foram definidas as palavras-chave para a busca de artigos nas plataformas Google Acadêmico, Scielo e Portal Capes. As palavras-chave utilizadas foram: método fônico, métodos de alfabetização, consciência fonológica, aquisição da leitura, TEA.

A partir dos dados obtidos, realizou-se a análise e interpretação das informações para maior compreensão e aprofundamento sobre o tema abordado.

\section{RESULTADOS E DISCUSSÕES}

Esta pesquisa possibilitou algumas constatações. A primeira delas refere-se aos estudos sobre a alfabetização e a aprendizagem de crianças com TEA. O histórico dessas pesquisas nos mostra o quanto os estudos evoluíram e apresentam cada vez mais especificidades sobre o universo das crianças autistas, sobretudo, sobre seus processos de aprendizagem. Nossa constatação é de que esses estudos evoluíram em função dos avanços tecnológicos que andam junto da ciência e, principalmente, do despertar da sociedade em relação a essa patologia. Antes as pessoas omitiam suas crianças, hoje elas brigam por seus direitos assistenciais e de aprendizagens.

Outro aspecto constatado diz respeito ao conceito do método fônico e as implicações na alfabetização de crianças com TEA. Descobrimos que o método fônico alfabetiza através dos sons das letras, facilitando e promovendo o desenvolvimento neurológico. O lado esquerdo do cérebro é responsável pela aquisição da leitura e a forma que ele sintetiza e interpreta as informações sensoriais advindas do ambiente no momento da leitura, mais especificamente as visuais e auditivas, são tidas como conhecimentos mínimos necessários para partir para a alfabetização. 
Após compreender a evolução histórica dos estudos a respeito do autismo e dos conceitos, buscamos, a partir da seleção de artigos, compreender o funcionamento do Método Fônico na alfabetização de crianças com TEA. Ficou evidenciado que o método fônico funciona bem para a aquisição da leitura de crianças autistas devido à questão da consciência fonológica que é a habilidade de manipular os sons da fala. Com a consciência fonológica acontece o desenvolvimento das habilidades cognitivas de suma importância para a independência dessas crianças.

\section{CONSIDERAÇÕES FINAIS}

O método fônico privilegia os grafemas e fonemas e, através de estímulos visuais e auditivos, a criança com TEA adquire uma maior facilidade no processo de aquisição da leitura, melhorando a dicção, entendendo tudo que se fala e se escreve, e que esses sons são definições de nomes de objetos e pessoas. Assim, essas crianças percebem a função da leitura e estabelecem uma sintonia sobre como se lê e o que percebe a sua volta.

Acompanhar os avanços tecnológicos é parte crucial nesse processo e fica evidente a necessidade de se continuar o estudo, já que a ciência e a educação, lado a lado, promove uma melhor qualidade de vida para essas crianças. Todos os métodos de alfabetização devem ser estudados para que seja escolhido o mais adequado, levando em consideração que cada criança com TEA é única e tem necessidades e habilidades diferentes. Não se pode negar a necessidade de estudo contínuo, capacitação, e um olhar diferenciado sobre cada método e cada criança com TEA.

\section{REFERÊNCIAS}

APA. American Psychiatric Association. Manual diagnóstico e Estatístico de Transtornos Mentais. DSM-IV-TR. 5. ed. Porto Alegre: Artmed, 2014.

CAPOVILla, Alessandra G. S.; CAPOVILlA, Fernando C.. Alfabetização: método fônico. 4. ed. São Paulo: Memnon, 2007.

COSENZA, M. Ramon; GUERRA, B. Leonor. Neurociência e educação: como o cérebro aprende. Porto Alegre: Artmed, 2011. 
CRUZ, Vitor. Sistema de Avaliação Cognitiva na Avaliação da Leitura de Crianças do $1 .^{\circ}$ Ano do $1 .^{\circ}$ Ciclo do Ensino Básico. In: NORONHA, A. P.; MACHADO, C.; ALMEIDA, L.; GONÇALVES, M.; MARTINS, S.; RAMALHO, V. (Org.). Actas da XIII Conferência Internacional de Avaliação Psicológica: Formas e Contextos. Braga: Universidade do Minho. Psiquilíbrios Edições, 2008. Disponível em: http://www.casadaleitura.org./. Acesso em: 30 Mar. 2011.

FAJARDO, Vanessa. Aluno com síndrome de Asperger é desafio para educação inclusiva. São Paulo: Portal G1, 26 jun. 2010. p. 1-3.

FISCHER, Steven Roger. História da leitura. Trad. Cláudia Freire. São Paulo: Editora da UNESP, 2006.

FREIRE, P. A importância do ato de ler em três artigos que se completam. $51^{\mathrm{a}}$ ed. São Paulo: Editora Cortez, 2011.

FREIRE, P. Educação como prática da liberdade. $41^{\text {a }}$ ed. Rio de Janeiro: Paz \& Terra, $2017 \mathrm{a}$.

FREIRE, P. Pedagogia da autonomia: saberes necessários à prática educativa. $55^{\mathrm{a}} \mathrm{ed}$. Rio de Janeiro: Paz \& Terra, 2017b.

FERREIRO, E. Reflexões sobre alfabetização. São Paulo: Cortez, 1985.

FERREIRO, E. Literacy development: psychogenesis. In: GOODMAN, Y. M. How children construct literacy: Piagetian perspectives. Newark: International Reading Association, 1990. p.12-25.

FERREIRO, E. Com todas as letras. São Paulo: Cortez, 1993.

KLIN, A. Autismo e Síndrome de Asperger: uma visão geral. In: Revista Brasileira de Psiquiatria. 28 (supl I): S3-11, 2006.

McCANDLISS, Bruce. Brain and Language. Stanford: Stanford News, 28/05/2015.

MELLO, Ana Maria S. Rosa. Autismo: guia prático. 5 ed. SãoPaulo: AMA, 2004.

MORTATTI, M. R. L. História dos métodos de alfabetização no Brasil. Portal MEC, 2006.

ORRÚ, Sílvia Ester. Autismo, linguagem e educação: interação social no cotidiano escolar. Rio de Janeiro: WAK, 2007. 
SCLIAR-CABRAL, L. Evidências a favor da reciclagem neuronal para a alfabetização. Letras de Hoje, v. 45, n. 3,p. 43-47, 2010.

SOARES, Magda. Letramento e Alfabetização: as muitas facetas. Revista Brasileira de Educação, 2004, n 25.

ZORZI, Jaime; CAPELLINI, Simone. Dislexia e outros distúrbios da leitura e escrita: letras desafiando a aprendizagem. São José dos Campos-SP: Pulso Editorial, 2008. 